\title{
Urban compactness and growth patterns in Spanish intermediate cities
}

\author{
Carlos Jiménez Romera ${ }^{1}$, Agustín Hernández Aja ${ }^{1}$, \\ Mariano Vázquez Espí \\ ${ }^{1}$ Departamento de Urbanística y Ordenación del Territorio, Escuela Técnica Superior de \\ Arquitectura de Madrid. Universidad Politécnica de Madrid. Madrid, Spain \\ ${ }^{2}$ Departamento de Estructuras y Física de la Edificación, Escuela Técnica Superior de \\ Arquitectura de Madrid. Universidad Politécnica de Madrid. Madrid, Spain \\ E-mail: carlos.jimenez.romera@gmail.com, agustin.hernandez@upm.es, \\ mariano.vazquez.espi@upm.es
}

\begin{abstract}
Contemporary processes of urbanization have outpaced the traditional notion of city. Connectivity has become a distinctive characteristic of urban spaces, so that networked cities don't rely anymore on continuous urbanized areas, but on connections that rarely leave a direct spatial footprint. The new spatial structure of urban areas include greater inter-penetration of built-up and open spaces, and the emergence of urban enclaves, which can be spatially isolated despite being functionally connected to a city. In order to study these enclaves and their impact on urban form, a sample of 47 Spanish functional urban areas was examined, ranging from 36,000 to 6.0 million inhabitants. Land use polygons provided by SIOSE were grouped into three main categories (residential, non-residential and urban infrastructure) and cross-matched with functional urban areas defined by AUDES (an iterative method than combines morphological and functional criteria) in order to calculate compactness proximity index, gross and net density. Factors that influence urban compactness were identified: most northern and some coastal urban areas display a low compactness which can be attributed to orographic conditions; bigger cities tend to display high compactness, but smaller ones display a great diversity of values, from the highest to the lowest. A further analysis of small and intermediate cities helped to identify two complementary mechanisms of urban growth, spatial expansion of core areas and functional integration of peripheral nuclei, whose ocurrence in different proportions can explain the variation of compactness in the studied sample.
\end{abstract}

Keywords: Urban compactness, urban growth patterns, intermediate cities

\section{Introduction}

Since Industrial Revolution, urban forms have suffered profound transformations. The urban growth associated to the new technical and economic reality of industrial cities created new spatial entities, named 'conurbations' by Geddes (1915), from the coalesce of formerly separated cities and towns. In 20th century, this impressive urban growth defined new low-density and discontiguous forms of urbanization, satellite cities and suburbs, that began to challenge the traditional notion of urban form. The expansion of urban footprint, including facilities and infrastructures, has produced a topological inversion of the landscape of most urbanized regions: there is no more an unlimited rural space surrounding a discrete urban entity, but an assemblage of strongly interlinked urban spaces that cross and 
break increasingly fragmented and encircled rural spaces (Margalef, 2005). At the same time, rural spaces tend to host a growing set of urban facilities and be home to a growing population of urban commuters, a proccess named 'rururbanization' by Bauer \& Roux (1976). This interpenetration of rural-urban realities supposes a challenge to the definition of urban form, as the city is no longer defined by a clearly differentiated space, but by a set of physical and virtual networks linking spatially-separated urban spaces (Dematteis, 1991; Dupuy, 1992; Corboz, 1994; Ascher, 1995). This new urban reality lacks definable boundaries, and the definition of urban space shifts to functional criteria: "families create their own 'cities' out of the destinations they can reach (usually travelling by car) in a 'reasonable' length of time" (Fishman, 1990). In any case, this functional vision of the urban space is already implied in the traditional notion of metropolitan area. The US Bureau of the Census firstly introduced functional criteria in 1964 to define Standard Metropolitan Statistical Areas (SMSA), based on the commuting flows, although without totally abandoning previous demographic, morphological and socio-economic criteria. Later, Fox \& Kumar (1965) proposed Functional Economic Areas, defined from the labor market extension of the central cities; Berry et al. (1968) conducted an analysis of commuting movements of the 1960 census, noting that while $66 \%$ of the US population resided in metropolitan areas, this figure rose to $87 \%$ if their commuting areas were included. All these approaches were conceptualizing the urban area from the labor market and daily commuting (Berry, 1973), or spatial self-containment of employment supply and demand (Smart, 1974; Hall \& Hay, 1980), and in such terms the metropolitanization and suburbanization of Western Europe began to be analyzed (Chesire \& Hay, 1986; Chesire, 1995). Currently, the US Bureau of the Census proposes differentiated methods for distinguishing rural and urban areas, on the one hand, and for defining metropolitan areas. Demographic and morphological criteria are usedf to differentiate urban and rural areas, while the definition of metropolitan area has a fundamentally functional base, although it is always derived from an urban core. Thus a metropolitan area may include both urban and rural areas, while an urban area may not belong to any metropolitan area. In the European Union, the ESPON project manages several types of territorial units, distinguishing between morphological units and functional units that are defined from the former. Morphological Urban Areas are defined by demographic criteria (population and population density) from existing administrative units, with various corrections, while Functional Urban Areas are derived from the former, incorporating those municipalities that have more than $10 \%$ of workers employed in the central core. Finally, Eurostat, the Urban Audit program and the OECD are concertedly working on a harmonized definition for all developed countries: the enlarged urban areas (Larger Urban Zones, LUZ), which corresponds to the traditional concept of Metropolitan Areas. Its delimitation follows a procedure similar to that of functional urban areas, although its central core is not defined from the density and population values of administrative units, but from the cells of an 1-kilometer orthogonal grid.

Despite all these efforts, the concept of labour market-related metropolitan area has not challenged the traditional notion of urban space, still asociated to a continuous built-up area, specially when comparing urban areas at international or global scale, where there is no consistent definition of metropolitan areas. The use of GIS and remote sensing technology has improved the access to global harmonized data and boosted the morphological study of greater urban areas (Angel et al., 2016; Demographia, 2017), but these studies fail to incorporate the new challenging definitions of urban nature and space, while displaying a bias towards greater urban areas that obscure any possible influence of city size in urban form.

\section{Methodology}

The main objective of this study is to unveil the relationship between city size and urban form, trying to answer the question of how urban growth modifies urban form, in a context or 


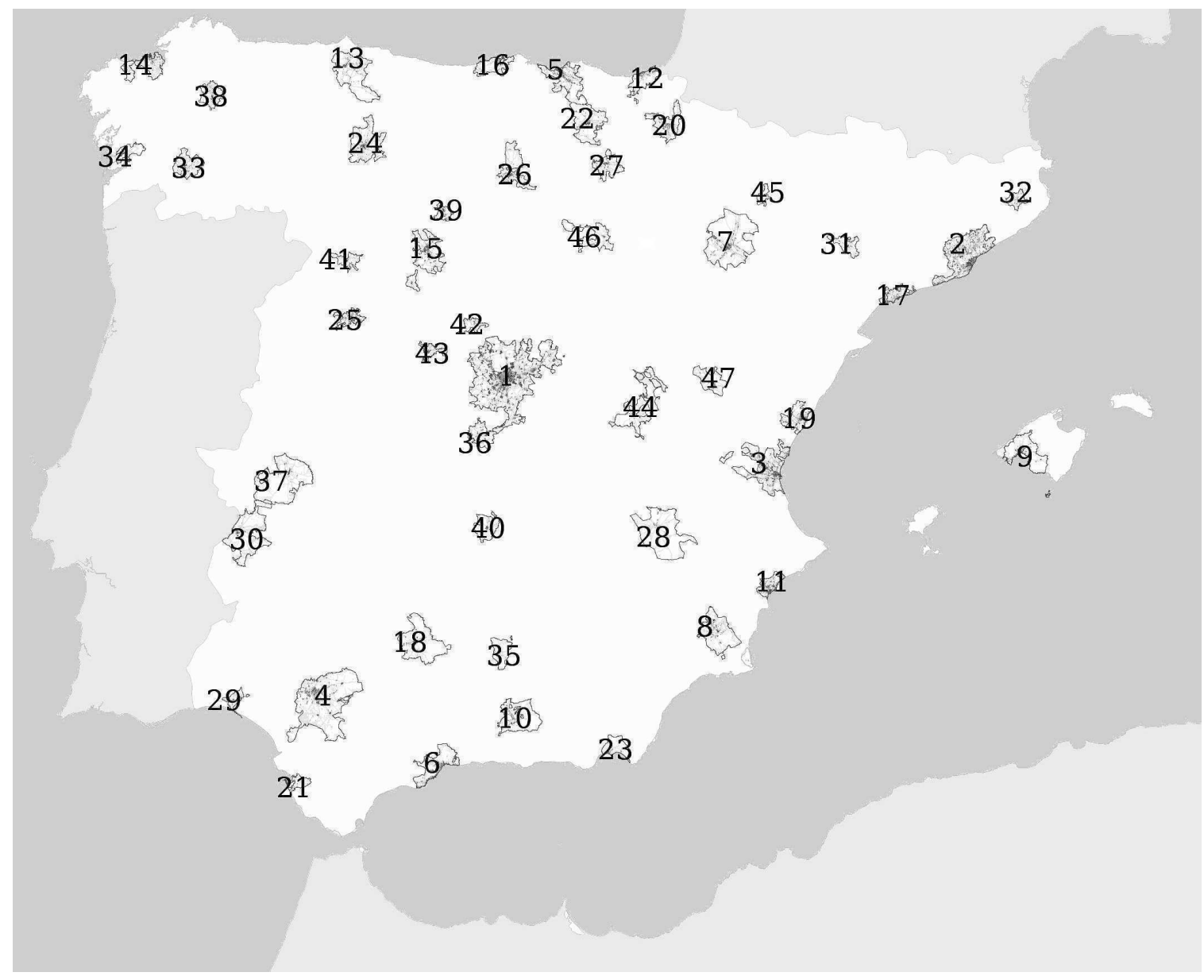

Figure 1.

The analized sample of functional urban areas

growing integration of rural and urban spaces, functions and population. In order to fulfil this objective, a wide sample of Spanish cities and towns was selected, showing different sizes and geographical contexts, but sharing a common legal frame and urban culture. It also was necessary to search for scale-independent spatial metrics that could be adapted to urban areas of such different size and population.

The sample includes all the Spanish provincial capitals (Figure 1), which have since been operating as administrative centers since 1833 , and have developed a central role in the process of urbanization of the country, becoming the main population center and urban referent of their respective territories. On the other hand, the size of these urban areas is correlated to a large extent with the demography of their surroundings: the largest cities are situated in the most populated areas, while smaller cities are usually in less populated regions.
Delimitation of urban areas

There is a great variety of methodological investigations on the delimitation of urban areas in Spain that adapt methods from international organisms or assume original approaches. Some works by the public administration make explicit a series of criteria of delimitation, but in fact they show no precise methodology, as they are based to a great extent on expert opinion, without ruling out criteria of political expediency. However, most of the works are academic studies based on detailed methods, and among them, more than half develop different variants of functional delimitation based on the labor market data from the 2001 Census, which detail the municipality of origin and destination of these daily work travels (Jiménez, 2015: 71-79).

On this common basis, each approach uses a different definition of the central core, employs 
different interaction thresholds to incorporate new municipalities and applies the process in one or several iterations. The starting point is usually a large municipality (Roca et al., 2005), or a set of municipalities, defined by the continuity of the urban fabric (Ruiz, 2011) or by self-containment of the local labour market (Roca et al., 2012). The incorporation procedure is the most important parameter to define the extension of the metropolitan area: the more flexible, iteratively applied criteria offers the greatest extensions, while more stringent criteria, together with a more restricted iteration, reduce the extent to a minimum.

The methodology that offers more extensive urban areas (Roca et al., 2005) is based on the pursuit of the maximum self-containment of the labour market area. This approach ends up offering the most disturbing results, by presenting large rural extensions as integrated into huge metropolitan areas. Paradoxically the low population of these territories makes them more dependent on the jobs available in the cities, so that an theoretically undisputable rural territory houses a population that has much of an urban lifestyle. At the opposite extreme, the AUDES project (Ruiz, 2011), without renouncing a functional conceptualization of the metropolitan area, applies much stricter morphological restrictions, displaying a much more conservative picture.

The AUDES method consists of an iterative process in which an urban nucleus is identified (based on data from Corine Land Cover 2006) with a population of at least 10,000 inhabitants. The degree of functional integration of contiguous municipalities is then evaluated according to an attraction ratio, calculated from the commuting travels collected by the 2001 Census. This ratio counts both the movements from the periphery to the center as those from the center to the periphery. The minimum ratio for joining the urban area is $25 \%$ (provided there is an absolute minimum of 200 transfers), and also includes the condition that there is spatial continuity. The next step in the process is to re-calculate the attraction ratio, but this time with adjacent urban areas, not isolated municipalities. These peripheral urban areas are incorporated into the greater urban area as urban subareas incase they have an attraction ratio of more than $25 \%$. The fourth and final step is to evaluate the interaction rate between adjacent urban areas, constituting what is named 'conurbation' in case the percentage of daily transfers between both areas exceeds $25 \%$ of the total daily transfers.

This iterative method is similar to those used in other studies, but it is also more demanding in terms of morphological criteria. Apart from the minimum population thresholds, each urban nucleus is strictly defined by its morphological attributes, and from that it is accepted the addition of a first crown of municipalities by exclusively functional criteria. The following iterative steps are no longer carried out with isolated municipalities, but with urban areas that have previously met both morphological and functional requirements.

\section{Urban form metrics}

There is a plethora of metrics designed to quantitatively describe urban form. Schwarz (2010) identifies two main groups, landscape metrics and socio-economic indicators, summing up more than 40 indicators used in different studies. However, most of these usually present strong correlations, so Schwartz finally uses seven main indicators to characterize European cities: "area of the discontinuous urban fabric, edge density, mean patch size, number of patches, compactness index of the largest patch, population number, population density" (Schwartz, 2010:41). Huang et al. (2007) use seven spatial metrics related to compactness, centrality, complexity, porosity and density, but correlation analysis shows strong relations among most of them, specially complexity, compactness and porosity, while density correlates only partially with some of them. Angel et al. (2016) calculate density, fragmentation and compactness metrics for a global sample of 200 cities, however fragmentation metrics strongly depend on scale-dependent factors, unsuitable fot a sample of such different size urban areas. For this estudy two metrics were chosen, as defined by Angel et al. (2016): gross density, or built area density, as "the ratio of the total population of the urban area and its built- 
up area, measured in persons per hectare"; compactness proximity index, defined as "the average beeline distance of all points in the equal area circle to city hall and the average beeline distance of all points in the urban extent" to the geometric centre of the built-up area (Angel et al., 2016:31)

Built-up area is calculated from SIOSE project, which covers the whole Spanish territory with a continuous mesh of polygons, characterized by the type of land use and cover. SIOSE database does not follow the traditional hierarchical classification of landcovers, but describes any polygon as a combination of one or more covers with their correspondent attributes and percentage of occupancy, with two associated superclasses: land cover and use (IGN, 2007). The SIOSE model includes a large number of cover types, but in this study we will resort primarily to a set of predefined associations within the category of artificial composites, covering the different types of urban fabrics, which have been grouped in three broad categories: mixed urban fabric, including residential areas (UCS, UEN, UDS), specialized urban fabric (industry: IPO, IPS, IAS; tertiary sector: TCO, TCH, TPR, TCG; urban facilities: EAI, ESN, ECM, EDU, EPN, ERG, ECL, EDP, ECG, EPU); and infrastructure (transportation: NRV, NRF, NPO, NAP; telecommunications: NTC; water supply: NDP, NDS, NCC; waste management: NVE, NPT).

\section{Measurement and analysis}

Gross density values vary from Teruel's 17.34 inhabitants/hectare to Cadiz's 94,21 inhab/ Ha. Apart from these extreme two cases (and Lleida, with a density similar to that of Teruel), the rest of the urban areas are in the range of 25-70 inhab/Ha. It is possible to distinguish, in any case, three large groups: the smaller urban areas $(<100,000$ inhabitants $)$ are in a range of densities of 25-40 inhab/Ha; larger urban areas $(>500,000$ inhabitants) display higher densities: between 40 and 70 inhab/Ha; finally, intermediate cities (between 100,000 and 500,000 inhabitants) are those that present the greatest diversity, with examples of maximum and minimum density, and occupying the entire range from 25 to $70 \mathrm{inhab} / \mathrm{Ha}$.

Although largest urban areas display higher values of density than smallest, the intermediate range displays the greatest variability, and one of them, Cadiz, has the highest density of the sample. Apart from this case, which could respond to extraordinary conditions, the highest values of density correspond to Barcelona, Bilbao, Donosti and Pontevedra, between 71 and 65 inhab/Ha, with populations between 4.5 million and 126,000 inhabitants. Thus, the sample shows the absence of small urban areas with high gross density and large urban areas with low gross density, while intermediate urban areas cover the full range of densities, reaching extreme values, both above and below.

On the other hand, compactness values obtained for the sample vary within the range from $20 \%$ to $55 \%$. Smaller urban areas display both the minimum and maximum values of compactness, while as the size of urban areas increases, the range of variation narrows, increasing the minimum values. The areas of Madrid and Barcelona have a compactness very close to the maximum values, but smaller urban areas (Alicante, Salamanca, Ávila and Huesca) are the ones that present the highest compactness. These values are relatively low compared to other studies (Angel et al., 2010), but this is due to the methodology used: urban infrastructures are not being computed, so that even in an area of continuous urbanization the spaces dedicated to these infrastructures appear as empty spaces. This methodology allows us to distinguish between those infrastructures integrated within the urban space versus those located on the periphery or in the vicinity of the urbanized area.

Gross density and compactness have a high degree of independence (Figure 2), with examples of low density and low compactness (Teruel), low density and high compactness (Avila), high density and low compactness (Oviedo, Santander, Pontevedra), and high density and high compactness (Barcelona, Bilbao). The obtained values of density and compactness allow to re-evaluate the traditional typology of Spanish cities, which is articulated around the geographical location: 


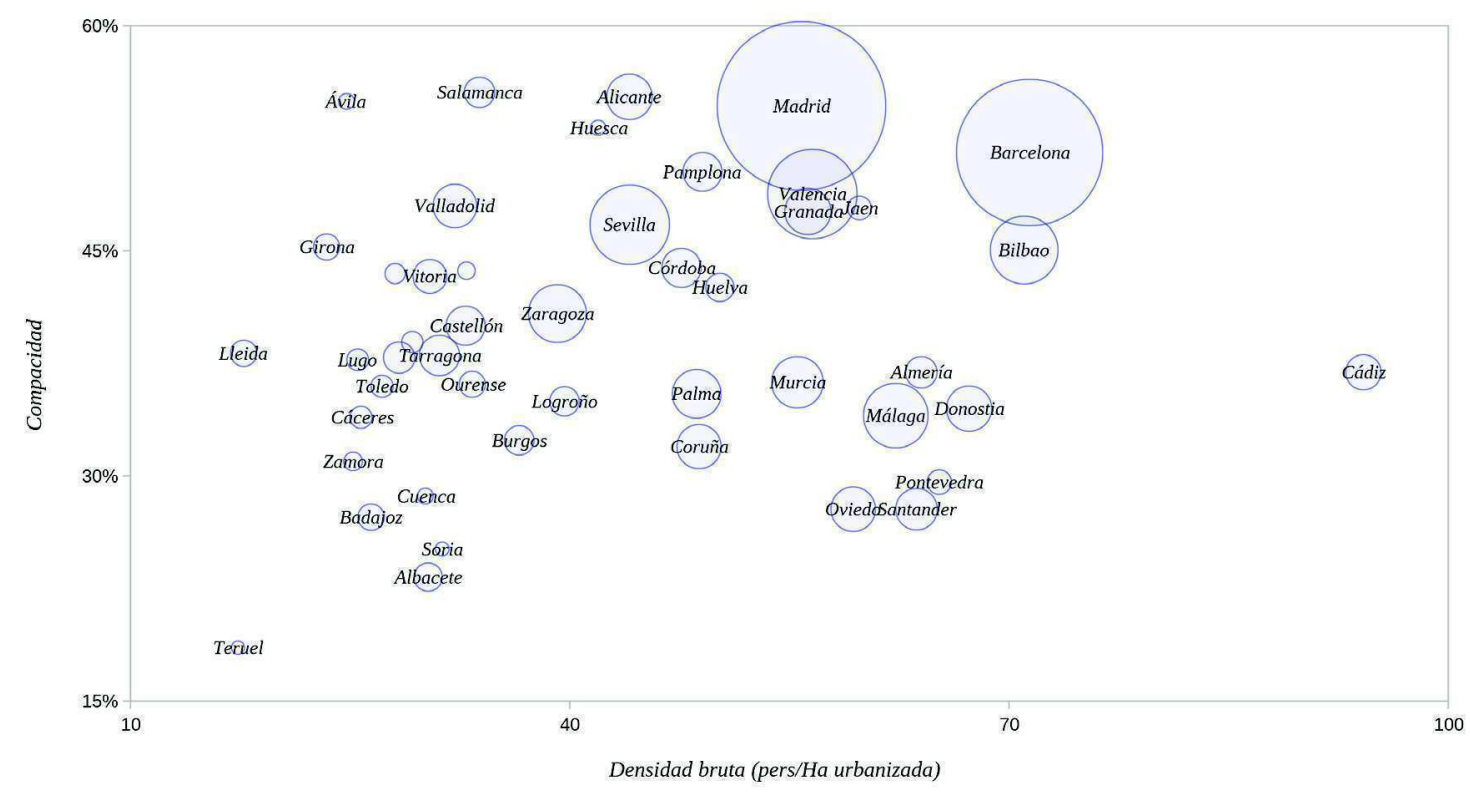

Figure 2.

Urban areas classified in terms of density and compactness

Mediterranean, Cantabrian and Inland cities. As a summary we can confirm the traditional groupings in terms of typology of cities, but density and compactness values offer a quite novel description.

Inland urban areas are characterized by a low gross density (17-39 inhab/Ha), a pattern that only Andalusian areas, northern Ebro Valley cities (Pamplona and Huesca) and Madrid, the largest area of the whole sample (55 inhab/Ha), break. On the contrary, compactness values are the most diverse, from the minimum of Teruel $(19 \%)$ to the maximum of Salamanca $(55 \%)$.

Urban areas of the northern coast of Spain (including the Atlantic capitals of Galicia), on the other hand, are characterized by high values of gross density (48-71 inhab/Ha) and low compacities (28-34\%). Only Bilbao, the largest urban area of this group, has a significantly high compactness $(45 \%)$.

Mediterranean cities display a fairly wide variation in gross density values (31-71 inhab/ $\mathrm{Ha}$ ), with larger urban areas showing the highest values, while compactness values are in the mid-high range (35-51\%). In the case of Andalusian urban areas, all of them have relatively high gross density values (44-94 inhab/Ha), while compactness values are also in the mid-high range (34-48\%).

From the former, some factors influencing urban compactness can be identified: most northern urban areas display a low compactness which can be attributed to orographic conditions, while southern and Mediterranean urban areas tend to be more compact. On the other hand, bigger cities tend to display high compactness, but smaller ones display a great diversity of values, from the highest to the lowest, that still have to be explained.

Different patterns of growth in intermediate cities

In contrast to the relative homogeneity of the large urban areas, the smaller ones present an important variability of both density and compactness (Figure 3). On the one hand, Avila and Jaen are typical examples of a Mediterranean-type compact city, with the bulk of the urbanized area grouped in the urban center and much smaller areas in the vicinity, maintaining a very similar total area and extent (around 2,000 Ha and between 2 and $3 \mathrm{~km}$ of average distance to the center), although Jaen has more than twice as many inhabitants as Avila. In front of these, Pontevedra and Teruel have urbanized areas of similar size (also around 2,000 $\mathrm{Ha}$ ), but with average distances to the center of almost 5 and 6 kilometers respectively. The lower compactness of these 
Table 1.

Gross density and compactnes of 47 Spanish urban areas

\begin{tabular}{|c|c|c|c|c|}
\hline Urban area & Population & Built-up area (Ha) & Gross density (inhab/Ha) & Compacidad \\
\hline Madrid & 6.003 .662 & 107530,17 & 55,83 & $54,64 \%$ \\
\hline Barcelona & 4.516 .079 & 63245,49 & 71,41 & $51,55 \%$ \\
\hline Valencia & 1.689 .835 & 29871,78 & 56,57 & $48,78 \%$ \\
\hline Sevilla & 1.335 .740 & 30285,48 & 44,10 & $46,73 \%$ \\
\hline Bilbao & 969.327 & 13644,64 & 71,04 & $45,05 \%$ \\
\hline Málaga & 881.008 & 14147,22 & 62,27 & $34,01 \%$ \\
\hline Zaragoza & 705.267 & 18012,05 & 39,16 & $40,82 \%$ \\
\hline Murcia & 560.442 & 10089,60 & 55,55 & $36,23 \%$ \\
\hline Palma & 501.898 & 10313,11 & 48,67 & $35,46 \%$ \\
\hline Granada & 452.238 & 8036,96 & 56,27 & $47,62 \%$ \\
\hline Alicante & 437.148 & 9916,11 & 44,08 & $55,25 \%$ \\
\hline Donostia & 431.744 & 6417,46 & 67,28 & $34,48 \%$ \\
\hline Oviedo & 417.841 & 7038,96 & 59,36 & $27,78 \%$ \\
\hline Coruña & 410.972 & 8416,80 & 48,83 & $31,95 \%$ \\
\hline Valladolid & 402.076 & 13508,36 & 29,76 & $38,61 \%$ \\
\hline Santander & 364.883 & 5729,49 & 63,69 & $27,78 \%$ \\
\hline Tarragona & 343.147 & 11034,56 & 31,10 & $38,02 \%$ \\
\hline Córdoba & 324.658 & 6815,66 & 47,63 & $43,86 \%$ \\
\hline Castellón & 322.222 & 9796,59 & 32,89 & $40,00 \%$ \\
\hline Pamplona & 320.149 & 6524,86 & 49,07 & $50,25 \%$ \\
\hline Cádiz & 262.459 & 2785,96 & 94,21 & $36,90 \%$ \\
\hline Vitoria & 240.929 & 7912,42 & 30,45 & $43,29 \%$ \\
\hline Almería & 209.635 & 3275,02 & 64,01 & $36,90 \%$ \\
\hline León & 207.991 & 7336,06 & 28,35 & $37,88 \%$ \\
\hline Salamanca & 196.553 & 5808,57 & 33,84 & $55,56 \%$ \\
\hline Burgos & 184.257 & 5040,82 & 36,55 & $32,36 \%$ \\
\hline Logroño & 182.487 & 4603,37 & 39,64 & $34,97 \%$ \\
\hline Albacete & 169.649 & 5592,83 & 30,33 & $23,26 \%$ \\
\hline Huelva & 168.584 & 3354,51 & 50,26 & $42,55 \%$ \\
\hline Badajoz & 147.553 & 5581,93 & 26,43 & $27,25 \%$ \\
\hline Lleida & 145.407 & 8200,45 & 17,73 & $38,17 \%$ \\
\hline Girona & 144.404 & 6174,08 & 23,39 & $45,25 \%$ \\
\hline Ourense & 144.013 & 4319,58 & 33,34 & $36,10 \%$ \\
\hline Pontevedra & 126.095 & 1932,71 & 65,24 & $29,59 \%$ \\
\hline Jaen & 120.070 & 2008,16 & 59,79 & $47,85 \%$ \\
\hline Toledo & 103.731 & 3816,06 & 27,18 & $35,97 \%$ \\
\hline Cáceres & 103.028 & 4002,65 & 25,74 & $33,90 \%$ \\
\hline Lugo & 99.813 & 3910,64 & 25,52 & $37,74 \%$ \\
\hline Palencia & 96.526 & 3299,93 & 29,25 & $38,91 \%$ \\
\hline Ciudad Real & 86.346 & 3076,56 & 28,07 & $43,48 \%$ \\
\hline Zamora & 73.915 & 2933,12 & 25,20 & $30,96 \%$ \\
\hline Segovia & 64.543 & 1958,71 & 32,95 & $43,67 \%$ \\
\hline Ávila & 53.272 & 2151,63 & 24,76 & $54,95 \%$ \\
\hline Cuenca & 53.211 & 1765,68 & 30,14 & $28,65 \%$ \\
\hline Huesca & 49.312 & 1175,85 & 41,94 & $53,19 \%$ \\
\hline Soria & 40.494 & 1294,20 & 31,29 & $25,13 \%$ \\
\hline Teruel & 36.608 & 2110,74 & 17,34 & $18,55 \%$ \\
\hline
\end{tabular}




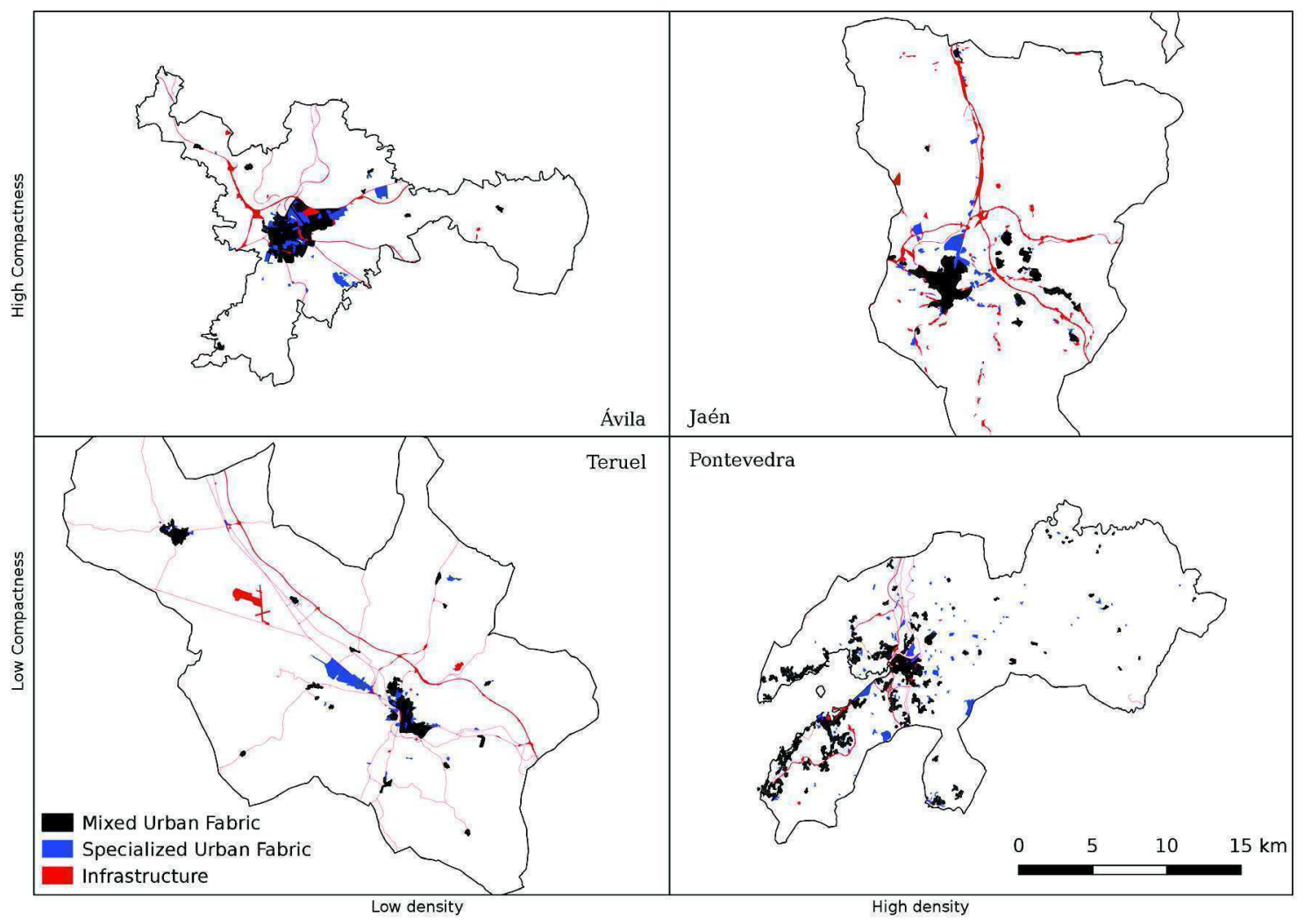

Figure 3.

Different patterns of density and compactness in intermediate cities

two urban areas is due to the existence of large non-urbanized areas interspersed between urbanized areas. In the case of Pontevedra this distribution corresponds to a specific type of dispersed settlement, typical of the Atlantic Europe and specifically the Galician region. The case of Teruel corresponds to another situation, since it is derived from the functional integration of two compact nuclei (Teruel itself and the neighboring municipality of Cella) and an extensive industrial estate located in the road that connects both. The 20 kilometers that separate both municipalities, combined with the small relative size of both nuclei explain the low compactness value $(18.55 \%)$.

\section{Conurbation vs. functional integration}

The process of urban growth and residential spread in Spain has more frequently implied the expansion of preexisting nuclei than the emergence of new suburban settlements. The urban areas of Castilla-Leon constitute a good sample of cities of intermediate and small size distributed over a fairly homogeneous geographic space, in terms of both topography and distribution of pre-industrial settlements. These urban areas also share similar values of gross density, but very different values of compactness (Figure 4).

The highest values of compactness correspond to Avila urban area, which only includes one municipality, and Salamanca, which has integrated a whole crown of nearby municipalities bordering the conurbation. On the other hand, the lowest compactness correspond to the less populated urban area of the sample, Soria, which has anyway managed to functionally integrate a number of relatively distant municipalities, and Zamora, which displays a structure very similar to that of Salamanca but with a much smaller size, so that the conurbation of the nuclei are very far from being achieved. Finally, the most populated area of the sample, Valladolid, also displays a high compactness, although lower than Salamanca, because after the intense conurbation with the first crown of municipalities, it has also integrated other municipalities further away from the central 


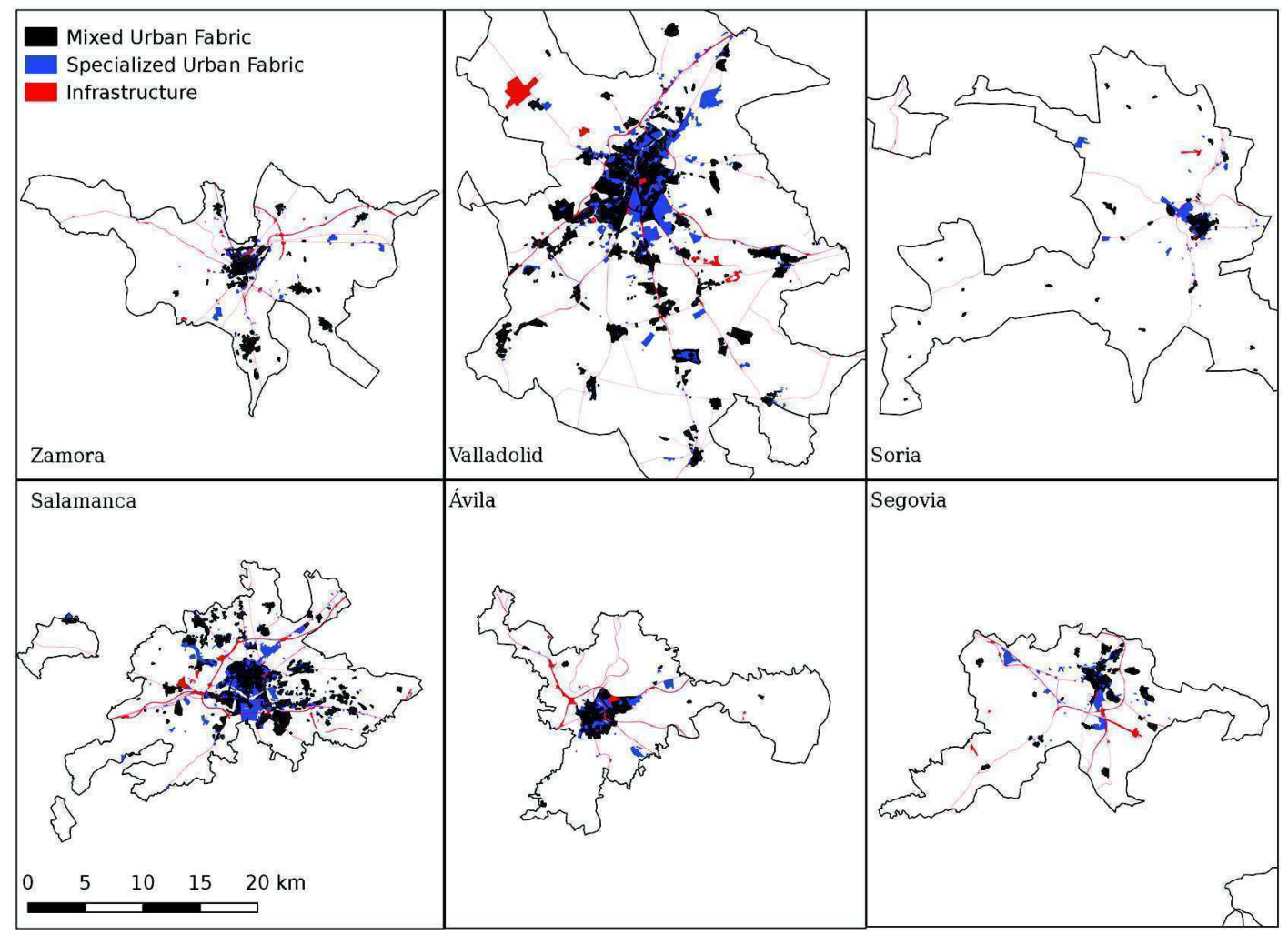

Figure 4.

Compactness and pattern growth in Castilla-León urban areas

core. In these urban areas we can observe the combination of two mechanisms of urban growth and how their different combination can explain the divergence in terms of compactness values: functional integration of distant nuclei drastically reduces compactness, while the subsequent growth of those nuclei tend to increase it.

\section{Conclusion}

This study has carried out a morphological characterization of urban areas mainly defined by functional criteria. The distinction between definition criteria and analysis variables is essential to avoid circularity: if we define an urban area as a dense and continuous space, no further analysis will show any space that is not dense and continuous. The urban functional space, however, is capable of showing itself as more or less dense, more or less compact.

The analyzed sample includes urban areas that share a social, cultural, economic, administrative and political context, but differ in size and geographical context. Geographic location seems to be the basic variable to explain the density-compactness pattern, while size seems to impose its own pattern when dealing with larger urban areas, where high density and compactness values are prevalent. Compared to the relative homogeneity of the large urban areas, the smaller ones present a much more varied range of density a compactness values.

The great variation of compactness values found in smaller urban areas can be explained because two different growth mechanisms take place in the peri-urban fringe that have opposite effects with respect to compactness: the functional integration of remote urban nuclei generates longer commuting distances with minor spread of the urban footprint, while the organic expansion of the central nucleus and previously integrated nuclei, tends to increase the urbanized area without increasing commuting distances. In greater urban areas these two mechanisms would not disappear, but the smaller relative size of the peri-urban fringe would substantially mitigate these fluctuations. 
Compared to other global studies that analyze broader and more diverse samples of large cities, this study is useful for evaluating the influence of size factor on the processes of urban growth and transformation of urban form. Similarly, comparing urban areas of such similar characteristics (within a peculiar urban culture as the Spanish one) allows to identify details of the urbanization process that are often overlooked when comparing cities of very different social, cultural, economic and political realities.

\section{References}

Angel, S.; Parent, J.; Civco, D. L. (2012) 'The fragmentation of urban landscapes: global evidence of a key attribute of the spatial structure of cities, 1990-2000', Environment and Urbanization, 24 (1), 249-283.

Angel, S.; Lamson-Hall, P.; Madrid, M.; Blei, A. M.; Parent, J.; Galarza Sánchez, N.; Thom, K. (2016). Atlas of urban expansion. 2016 Edition. NYU Urban Expansion Program at New York University; UNHabitat; Lincoln Institute of Land Policy. (http://www.lincolninst.edu/subcenters/ atlas-urban-expansion/), accesed 31 January 2017.

Ascher, F. (1995) Métapolis ou l'avenir des villes. (Paris: Éditions Odile Jacob.)

Bauer, Gérard; Roux, Jean-Michel (1976) La rurbanisation, ou la ville éparpillé. Paris: Ed. du Seuil.

Berry, Brian J. L.; Goheen, Peter G.; Goldstein, Harold (1968) Metropolitan area definition: a re-evaluation of concept and statistical practice. Washington DC: Bureau of the Census Working Paper 28.

Cheshire, Paul C. (1995) 'A new phase of urban development in Western Europe. The evidence from the 1980s' Urban Studies, 32 (7): 1045-1063.

Corboz, André (1994) 'Hyperville', Cahier 8, Givors: Institut pour l'Art et la Vie, Maison du Rhône, pp. 112-129.

Demographia (2017) World Urban Areas (World Agglomerations). 13th Annual Edition, April 2017. http://www.demographia.com/ db-worldua.pdf, accessed 24 May 2017
Dijkstra, L.; Poelman, H. (2015) European cities - the EU-OECD functional urban area definition. (http://ec.europa.eu/eurostat/ statistics-explained/index.php/European cities_\%E2\%80\%93 the EU-OECD_ functional_urban_area_definition), accessed 31 January 2017

Fishman, Robert (1990) “America's New City", The Wilson Quarterly, 14 (1): 24-55.

Fox, Karl A.; Kumar, T. Krishna (1965) "The functional economic area: delineation and implications for economic analysis and policy." Papers in Regional Science, 15 (1): 57-85.

Friedmann, J.; Miller, J. (1965) "The urban field." Journal of the American Institute of Planners, 31 (4): 312-320.

Geddes, Patrick (1915) Cities in evolution: An introduction to the town planning movement and to the study of civics. London: Williams $\&$ Norgate.

Hall, P.; Hay, D. G. (1980) Growth Centers in the European Urban System. London: Heinemann.

Huang, J., Lu, X. X., \& Sellers, J. M. (2007). "A global comparative analysis of urban form: Applying spatial metrics and remote sensing." Landscape and urban planning, 82 (4), 184-197.

IGN (2007) SIOSE, Sistema de Información sobre Ocupación del Suelo (http://www. siose.es/), accessed 31 January 2017.

Jiménez Romera, C. (2012) "La urbanización y lo urbano, realidades divergentes / Urbanism and urbanization, divergent realities." URBAN NS04: 15-26.

Jiménez Romera, C. (2015). Tamaño y densidad urbana: análisis de la ocupación de suelo por las áreas urbanas españolas. $\mathrm{PhD}$ dissertation, Universidad Politénica de Madrid. (http://oa.upm.es/39937/), accessed 31 January 2017.

Margalef, Ramón (2005) "Acelerada inversión en la topología de los sistemas epicontinentales humanizados." In: Naredo, J. M.; Gutiérrez, L. (ed.) (2005) La incidencia de la especie humana sobre la faz de la Tierra. Granada: Universidad de Granada, Fundación César Manrique, pp. 217-223

Roca Cladera, J. (2003) "La delimitación de la ciudad: ¿una cuestión imposible?" Ciudad y territorio. Estudios Territoriales, 135: 17-36. 
Roca Cladera, J.; Burns, M. C.; Moix Bergadà, M. (2005) Las Áreas Metropolitanas Españolas. Evolución 1991-2001. Barcelona: CPSV-UPC.

Roca Cladera, J.; Moix Bergadà, M.; Arellano Ramos, B. (2012) "El sistema urbano en España." Geocrítica: Scripta Nova, XVI, 395. http://www.ub.es/geocrit/sn/sn-395. htm

Ruiz, F. (2011) AUDES, Áreas Urbanas de España (http://alarcos.esi.uclm.es/per/fruiz/ audes/), accessed 31 January 2017.

Schwarz, N. (2010) "Urban form revisitedSelecting indicators for characterising European cities." Landscape and Urban Planning, 96 (1), 29-47.

Smart, M. W. (1974) Labour market areas: uses and definition. Oxford: Pergamon Press.

Soja, E. (2000) Postmetropolis Critical studies of cities and regions. Oxford: Blackwell Publishers.

Processing, Visualization and Transmission, 3DPVT 2002, Padua, Italy, pp. 526-531.

Servei d'Arqueologia de Barcelona (2015). Proyecto Barcelona Darrera Mirada: 8 Un passeig impossible. http://darreramirada. ajuntament.barcelona.cat/\#historia/8/1/ 